\title{
The ocular manifestations of multiple sclerosis
}

\section{Abnormalities of the afferent visual system}

\author{
W I McDonald, D Barnes
}

"[December 1822] ... My eyes were so attacked that when fixed upon minute objects indistinctness of vision was the consequence:Until I attempted to read, or to cut my pen, I was not aware of my Eyes being in the least attacked. Soon after, I went to Ireland, and without any thing having been done to my Eyes, they completely recovered their strength and distinctness of vision".

Augustus d'Esté

Visual symptoms, sensory or motor, are amongst the commonest manifestations of demyelinating disease. More than one third of patients with multiple sclerosis (MS) present with them and they occur at some stage in almost all. This paper, and a companion paper on disorders of eye movement are based on two decades of experience in the physician's clinic at Moorfields Eye Hospital. We have not attempted to analyse the whole clinical material, but present conclusions derived from numerous published studies based on it, emanating from Moorfields, the National Hospitals Queen Square and Maida Vale and the Medical Research Council's Hearing and Balance Unit.

\section{Acute optic neuritis}

Optic neuritis is the commonest cause of spontaneously reversible visual loss in young adults in populations of Northern European origin. It usually begins with discomfort around the eye which is increased by eye movement. Blurring of vision usually follows within a few days though it may precede the pain, which is only rarely severe. Visual loss evolves over a week or so to reach a maximum which varies from the trivial to the profound (no perception of light). Colour vision is altered early, colours being broken up in a pointillist manner, as MacKarell, ${ }^{2}$ a professional painter, has so poignantly illustrated. It soon fades so that the environment has a pale, grey, washed out appearance (fig 1). The general level of illumination appears low and depth perception is impaired.

and the Moorfields

Eye Hospital, London,

UK

W I McDonald

D Barnes

Correspondence to: Professor McDonald, Institute of Neurology, Wueen Square, Lon

Received 23 August 1991 and in revised form 31 December 1991. Accepted 8 January 1992 at which the patient is examined. Figures $2 a$ and $b$ show that occasionally a defect with a horizontal margin indistinguishable from that seen with ischaemic lesions may evolve over a week or two into a central scotoma. During the recovery phase, a typical central scotoma may become patchy and later leave an enlarged blind spot with an arcuate scotoma (figs $3 a, b$ ); fragments of this defect may persist indefinitely. ${ }^{3}$ Rarely, clearing of central vision may first result in the temporary appearance of a ring scotoma (fig 4).

Colour vision is almost invariably impaired and there is a relative afferent pupillary defect. Fundal examination is normal in about $50 \%$ of patients. In the remainder, variable swelling of the optic disc (papillitis) is present. After a month or so, pallor of the optic disc commonly develops, with variable loss of the retinal nerve fibre layer. Haemorrhages occur in less than $5 \%$ of patients and are never profuse, and the retina itself close to the disc is unchanged; if there is extensive peripapillary oedema with retinal folds and a macular star, the appearances suggest the rare condition of neuroretinitis which may not have the same implications for the development of multiple sclerosis. ${ }^{4}$ In about a quarter of patients with optic neuritis there are varying combinations of perivenous sheathing, leakage of fluorescein at angiography, and cells in the media. ${ }^{5}$ The vascular changes are almost always confined to

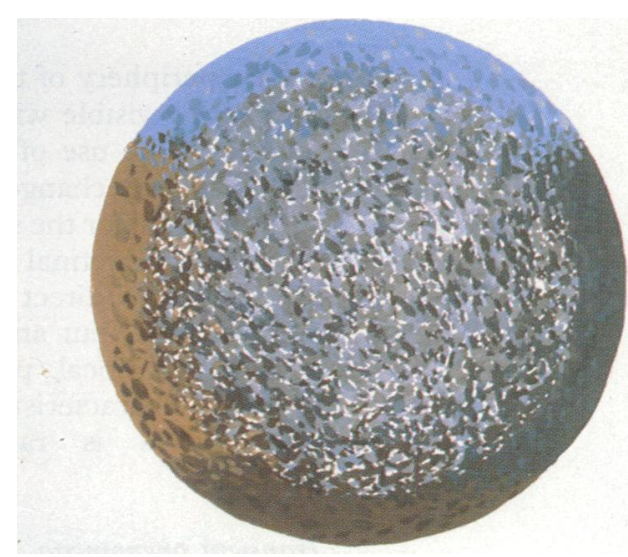

Figure 1 The Grey Blanket "The next day, upon waking I discovered that there was over the central zone of vision of my right eye, what seemed like a grey asbestos mat. Although there was peripheral vision I was disturbed to note that the grey swab occluded all light. I switched on the bedside light in the vain hope that intense lumination would somehow disperse the fog." (From Depictions of an would somehow disperse the fog." (From Depictions of Education in Art and Design.) 
Figure 2 Patient with acute optic neuritis. Note how the early quadrantic field defect (a) evolved over two weeks into a central scotoma (b).
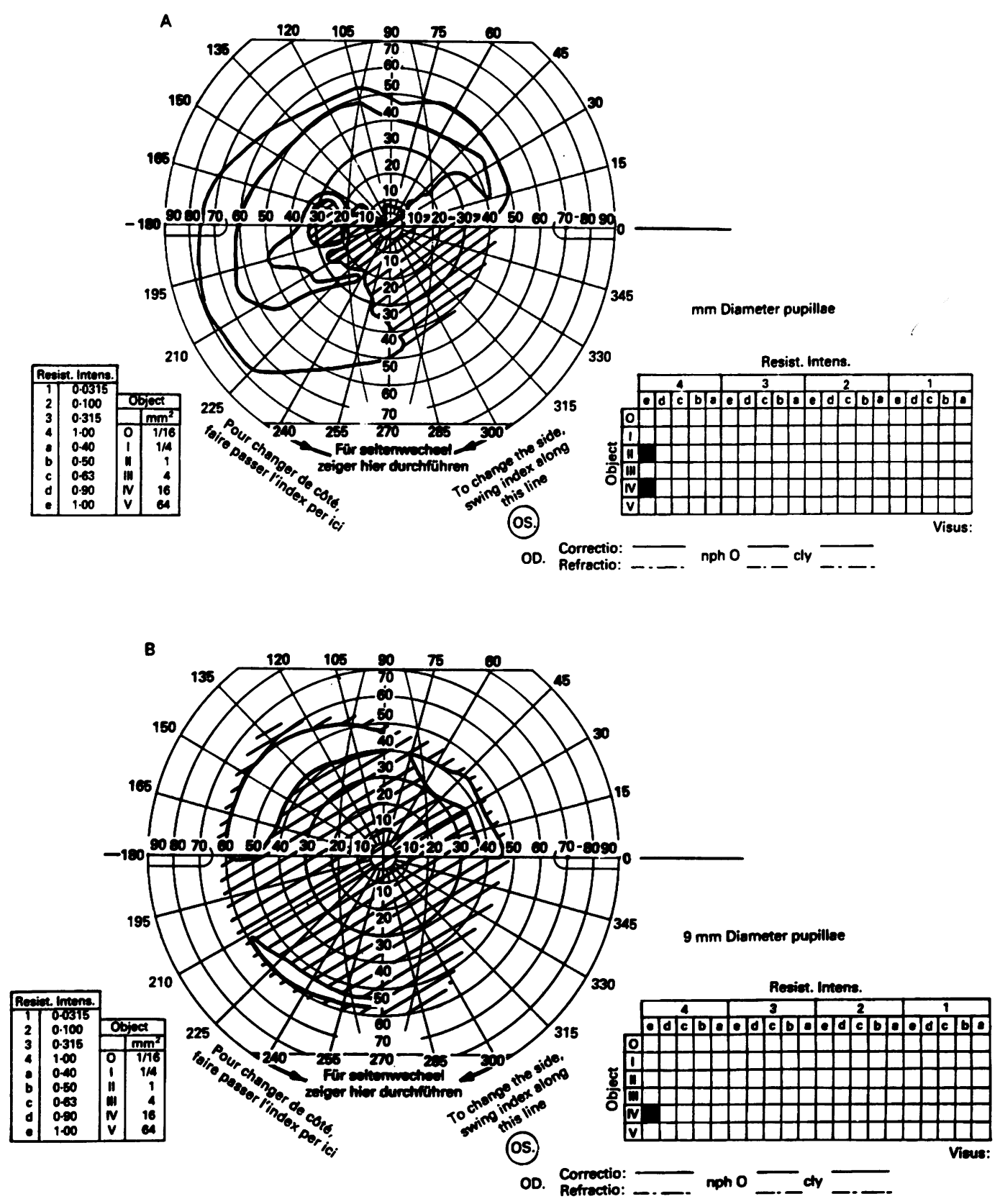

the far periphery of the retina and are usually not readily visible without full dilation of the pupil and the use of the indirect ophthalmoscope. These changes may be seen in the asymptomatic or the symptomatic eye, indicating that the retinal vascular involvement is probably not a direct consequence of the optic neuritis itself, but an independent expression of the multifocal perivenular inflammation which is characteristic of multiple sclerosis. The uveitis is rarely symptomatic (see below).

\section{Transient phenomena}

Three classes of short-lived symptoms are encountered. Phosphenes (flashes of light), often precipitated by eye movement are experienced by approximately one third of patients. ${ }^{56}$ Deterioration of vision induced by exercise, a hot meal or a hot bath (Uhthoff's phenomenon) is usually not encountered in the acute stage of optic neuritis, though it can rarely be the presenting feature of multiple sclerosis. This variability in vision is associated with a reduction in amplitude of the visual evoked potential, ${ }^{7}$ and can be partly accounted for by the extreme sensitivity of conduction in partially demyelinated fibres to small changes in temperature. ${ }^{8}$

A sense of disorientation in moving traffic is experienced by some patients and is probably due to the Pulfrich effect, a phenomenon attributable to unequal latencies between the two eyes which can be experienced in normal individuals by placing a neutral density filter over one eye: a pendulum swinging in one plane then appears to be describing an elipse. ${ }^{910}$

\section{Course and prognosis}

The patient with optic neuritis is anxious to have answers to two questions: "Will I get better?" and "Will it recur?" The physician (and sometimes the patient too) is also inter- 
Figure 3 Following acute patient, the large central scotoma (a) has resolved over six months to leave a discontinuous arcuate defect with an enlarged blind spot (b). optic neuritis in this
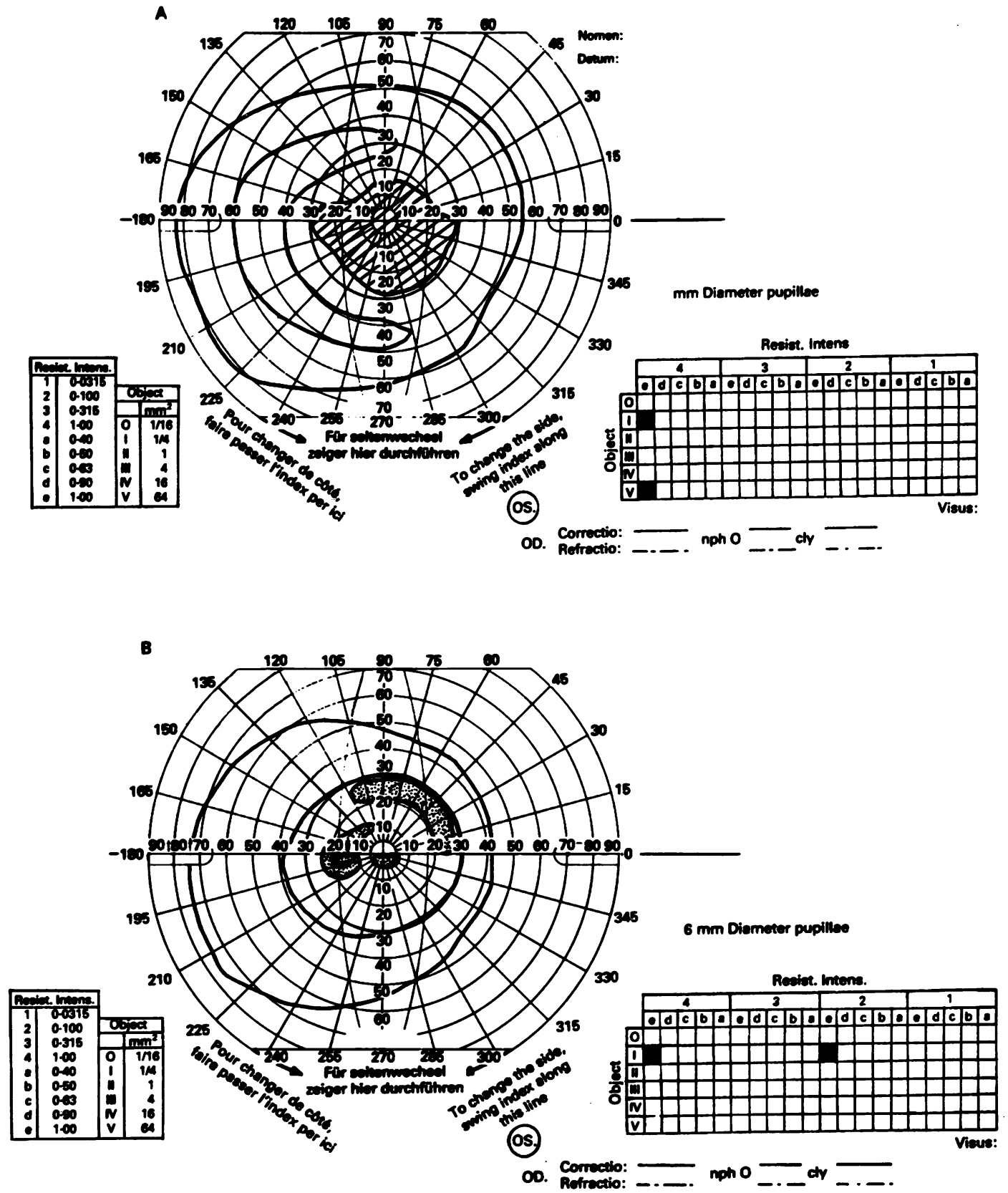

Figure 4 During recovery from acute optic neuritis, an earlier central scotoma (not shown) has evolved into a ring scotoma.

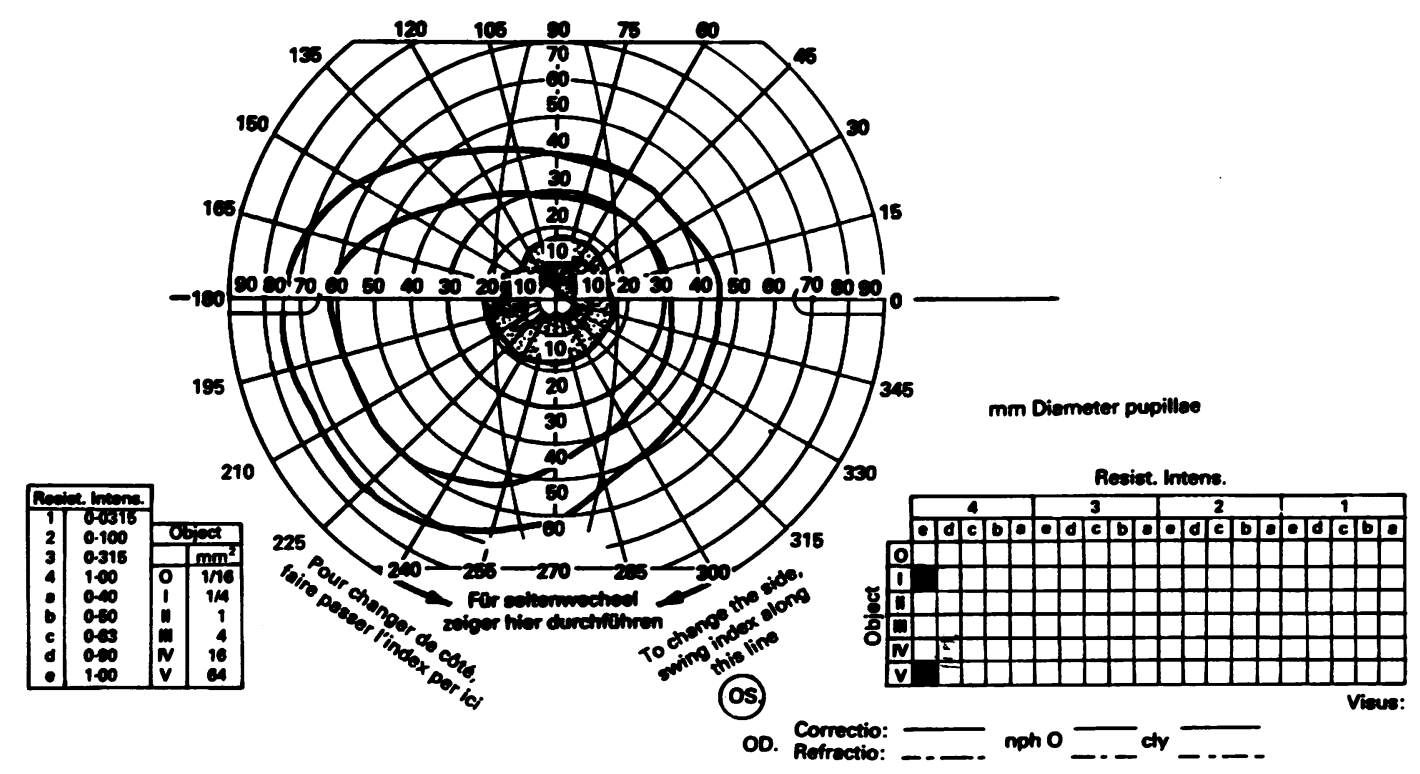


ested in the question: "Will the patient develop multiple sclerosis?"

Between 85-95\% of patients with acute optic neuritis make an excellent recovery to an acuity of $6 / 9$ or better over a period of $1-3$ months, though occasionally the recovery period is longer. Even if the final acuity is normal, patients may be aware of a range of residual symptoms, which are not, however, usually troublesome except when the patient's occupation or recreation requires optimum visual performance. Impairment of contrast sensitivity and colour vision are common ${ }^{11}$ and impairment of depth perception may interfere with playing ball games.

It is not possible to predict the likelihood of a residual deficit with any confidence on clinical grounds. Gould et al, for example, found that the worst visual acuity was unrelated to the likelihood of a persisting deficit. ${ }^{12}$ Recently, MRI of the optic nerve has provided evidence that physically long lesions (more than $1 \mathrm{~cm}$ ), particularly when they involve the portion of the nerve in the optic canal, are significantly associated with persistent visual impairment. ${ }^{13}$ Recurrence of optic neuritis, in either eye occurs in $20-36 \%$ of patients. ${ }^{14-16}$

\section{Risk of developing multiple sclerosis}

There is a considerable range of frequency of developing MS world wide. ${ }^{17} 18$ Not surprisingly, the frequency is low in populations in which multiple sclerosis is rare. For example, in Japan a frequency of $8 \%,{ }^{19}$ and in a white population in Chile, ${ }^{20}$ a frequency of $4.3 \%$ (1 of 23 patients) has been reported. In populations of Northern European origin living at high latitudes, however, multiple sclerosis is more frequent. In the United Kingdom probably about $75 \%$ of patients ultimately develop. multiple sclerosis, the majority doing so within the first five years after presentation. ${ }^{1521} \mathrm{~A}$ number of risk factors for the development of multiple sclerosis has been identified, but none is a wholly reliable guide. Rizzo and Lessell found that in Massachusetts the 15 year calculated risk for developing multiple sclerosis was $74 \%$ in females, but only $34 \%$ in males. ${ }^{16}$ The presence of perivenous sheathing carries a relative risk of 14 for developing multiple sclerosis after a mean follow up of 3.5 years.

Multiple silent cerebral lesions on MRI at presentation carries a high risk for the early development of multiple sclerosis: Miller et al found a nearly seven fold increase in risk of developing multiple sclerosis within a year. ${ }^{22}$ Five year follow up has revealed that $3 / 4$ of patients with silent lesions at presentation have developed the disease compared with less than $10 \%$ with normal brain MRI (S Morrissey; unpublished data). It must be emphasised, however, that multiple cerebral lesions on MRI (most of which eventually disappear) may be seen with monophasic acute disseminated encephalomyelitis, following which the risk of developing multiple sclerosis is very low. ${ }^{23} 24$ The diagnosis of multiple sclerosis cannot therefore be made on the basis of a single unenhanced MRI, and follow up is mandatory. Moulin et al found that the presence of oligoclonal bands in the CSF increased the risk of subsequent development of multiple sclerosis. ${ }^{25}$ HLA typing is of no practical value: although associations with A3, B7, DR2 and DR3 have been described, the results are not consistent. ${ }^{152627}$

\section{Pathophysiology}

Recent work making use of gadolinium (Gd)TPA enhanced MRI and evoked potentials has shed light on the mechanism of symptom production in acute optic neuritis. There is good evidence that the occurrence of $\mathrm{Gd}$ DTPA enhancement in immune-mediated demyelinating disease indicates the presence of inflammation. ${ }^{28-30}$ The earliest detectable event in the development of a new lesion in multiple sclerosis is an increase in permeability of the blood-brain barrier in association with inflammation. $^{29}$ Over the next few weeks oedema develops and is often extensive. ${ }^{3132}$ Inflammation ceases after approximately one month and over the next few weeks the oedema resolves to leave a small residual area of abnormal MRI signal.

Youl et al studied visual function in relation to MRI with and without Gd-DTPA enhancement and visual evoked potentials in patients recruited within two weeks of the onset of symptoms of optic neuritis. ${ }^{33}$ They found that Gd-DTPA enhancement (signifying inflammation) was present in all optic nerves examined at this early stage. After a month, enhancement had ceased in the majority. The presence of the main clinical features (visual loss, field defects, an afferent pupillary defect and pain) correlated significantly with the presence of inflammation. Of particular interest were the visual evoked potential (VEP) findings: there was a strong relationship between optic nerve enhancement and reduction in VEP amplitude (signifying conduction block). When enhancement subsided, however, the VEP showed consideable recovery, though with persistent delay presumably signifying demyelination. The dependence of visual acuity on intact optic nerve conduction as assessed by VEP amplitude, but not latency, is well established.${ }^{34}$ These experiments lead to the conclusion that the inflammatory process per se impairs conduction and that its resolution makes an important contribution to visual recovery. The possible mechanisms involved are reviewed by Youl et al. ${ }^{33}$

Demyelination probably does, however, contribute to some symptoms. The Pulfrich effect can be accounted for by slowing of conduction in one optic nerve, and the phosphenes on eye movement by abnormal excitability of demyelinated axons. ${ }^{35}$ The high risk of persistent visual impairment with lesions in the optic canal may be due to the occurrence of inflammation with accompanying oedema in a region where there is little room for expansion of the nerve. The ophthalmic artery also runs through the canal, and it is possible that the lasting deficit results from the addition of an ischaemic element to the direct effects of inflammation and demyelination. 


\section{Treatment}

Given that approximately $90 \%$ of patients make an excellent spontaneous recovery it will be difficult to demonstrate a therapeutic effect the end-point of which is a reduction in the number of patients with persisting visual loss. This is indeed the case, and no completed study is large enough to demonstrate such an effect. One might, however, expect steroids to be helpful in view of their anti-inflammatory properties and their capacity to reverse the blood-brain barrier defect (albeit temporarily) in multiple sclerosis. ${ }^{36}$ Several studies have shown that treatment with $\mathrm{ACTH}^{37} 38$ and retrobulbar triamcinolone ${ }^{12}$ shortens the duration of visual impairment. In view of the influence that length of the lesion and involvement of the nerve in the bony optic canal have on prognosis, a controlled trial of high dose intravenous methylprednisolone in this sub group has been initiated. A large multicentre trial of oral prednisone on unselected cases of optic neuritis is being carried out in the United States.

\section{Acute bilateral optic neuritis}

We have so far dealt only with acute unilateral optic neuritis. In adults, acute bilateral simultaneous optic neuritis is much less common than unilateral or sequential optic neuritis, and published studies are based on small numbers. Hierons and Lyle reported 11 cases who were reviewed after up to 30 years by Parkin et al. ${ }^{3940}$ The visual prognosis was poorer than for unilateral optic neuritis. Only two patients fulfilled the criteria for a diagnosis of multiple sclerosis, suggesting that this disease may be less common after simultaneously bilateral optic neuritis than after unilateral optic neuritis. Nevertheless, we see a few cases each year in whom multiple sclerosis follows acute bilateral simultaneous optic neuritis. The numbers in this study were small and the possibility that some of the patients were isolated cases of Leber's optic neuropathy could not, at that time, be excluded. The diagnostic assessment of such patients should now include both MRI (additional silent cerebral lesions are absent in typical Leber's hereditary optic neuropathy in males), ${ }^{41}$ and examination of mitochondrial DNA. ${ }^{42} 43$

\section{Childhood optic neuritis}

In children optic neuritis, when it is recognised, is usually bilateral. Small children with unilateral visual loss may not show behavioural change sufficient to attract the attention of their parents. There is a number of clinical differences from adult optic neuritis. ${ }^{17394445}$ The illness follows an infection such as measles, chicken pox and infectious mononucleosis in nearly half of cases and, not surprisingly, there is a seasonal variation with the greatest number presenting in April. Evidence of more generalised CNS involvement is not infrequently present in the form of drowsiness or fleeting neurological signs. The CSF is usually normal but may show a modest pleocy- tosis or raised protein content or both. MRI shows that occasional cases presenting with optic neuritis have bilateral cerebral lesions showing a marked tendency to resolution, typical of acute disseminated encephalomyelitis. ${ }^{24}$ Exceptionally, such cases may be seen in adult life. ${ }^{46}$ The prognosis for vision is excellent: in a follow up of up to 32 years persistently impaired acuity was found in only one eye in 19 patients. ${ }^{40}$

The risk of multiple sclerosis after childhood optic neuritis is much lower than in adults, ${ }^{45}$ not exceeding $15 \%$ in the United Kingdom where, as noted above, the risk for adults with unilateral optic neuritis is approximately $75 \%$.

\section{Progressive optic neuritis}

Though it occurs, progressive optic neuritis, unilateral or bilateral is rare and the diagnosis should only be made after careful exclusion of a compressive cause and long term follow up. Such patients should be kept under review indefinitely. Rarely, multiple sclerosis may present as progressive bilateral visual loss. ${ }^{47}$

\section{Involvement of the posterior visual path-} ways

At necropsy the optic chiasm, tracts and radiations commonly contain lesions. In the two thirds of patients with acute optic neuritis having multiple silent cerebral MRI lesions at presentation, the optic radiations are almost always involved. ${ }^{48}$ Occasionally, however, symptomatic acute homonymous hemianopias are encountered, and a recent MRI study provides evidence that in such cases the lesions are unusually large. ${ }^{49}$ We have not seen a clinically manifest bitemporal hemianopia as described by Traquair, ${ }^{50}$ though we have seen patients with acute unilateral optic neuritis who have evidence of involvement of the ipsilateral chiasm from Gd-DTPA enhancement or an abnormal evoked potential from the contralateral temporal field. The reasons for the infrequency of symptomatic posterior defects-which include the relationship between the anatomical disposition of the fibres and the perivenular orientation of the lesions, as well as the usual size of plaques - are discussed elsewhere. ${ }^{49}$

\section{Retinal vasculitis}

As previously mentioned, subclinical ocular inflammatory changes are found in about one quarter of patients with acute optic neuritis." Sheathing occurs in a slightly smaller proportion of patients with established MS. ${ }^{51}$ These retinal changes are only occasionally symptomatic $^{52}$ though we have seen one patient with clinically definite disease in whom recurrent retinal haemorrhage was so severe as to necessitate vitrectomy Confusion with sarcoidosis occasionally arises; spontaneous and more or less lasting remission of visual loss (the rule in optic neuritis) is much against the diagnosis of granulomatous optic neuropathy. ${ }^{53}$ 
1 Firth D. The case of Augustus d'Este. Cambridge, UK: Cambridge University Press, 1948.

2 MacKarell P. Depictions of an odyssey. Corsham, Wiltshire: National Society for Education in Art and Design, 1990:283-93.

3 Frisen L Hoyt WF. Insidious atrophy of retinal nerve fibres in multiple sclerosis. Arch Ophthalmol 1974;92:91-7.

4 Parmley VC, Schiffman JS, Maitland CG, Miller NR, Dreyer RF, Hoyt WF. Does neuroretinitis rule out multiple scleroris? Arch Neurol 1981;44:1045-8.

5 Lightman S, McDonald WI, Bird AC, et al. Retinal venous sheathing in optic neuritis. Brain 1987;110:405-14.

6 Davis FA, Bergen D, Schauf C, et al. Movement phosphenes in optic neuritis: a new clinical sign. Neurology 1976; 26:1100-4.

7 Persson HE, Sachs V. Visual evoked potentials elicitied by pattern reversal during provoked visual impairment in multiple sclerosis. Brain 1981;104:369-82.

8 Rasminsky $M$. The effects of temperature on conduction in demyelinated single nerve fibres. Arch Neurol 1973;28: 287-92.

9 Rushton D. Use of Pulfrich pendulum for detecting abnormal delay in the visual pathway in multiple sclerosis. abnormal delay in the visu.
Brain 1975;98:283-96.

10 Ell JJ, Gresty MA. Uniocular Pulfrich phenomenon: an abnormality of visual perception. $\mathrm{Br} f$ Ophthalmo 1982;66:610-13.

11 Mullen KT, Plant GT. Colour and luminance vision in human optic neuritis. Brain 1986;109:1-13.

12 Gould ES, Bird AC, Leaver PK, McDonald WI. Treatmen of optic neuritis by retrobulbar injection of triamcinolone. BM7 1977;1:1495-7.

13 Miller DH, Newton MR, van der Poel, et al. Magnetic resonance imaging of the optic nerve in optic neuritis. Neurology 1988;38:175-9.

14 Sandberg-Wollheim M, Bynke H, Cronqvist S, et al. A longterm prospective study of optic neuritis: evaluation of risk term prospective study of optic neuritis:

15 Francis DA, Compston DAS, Batchelor JR, McDonald WI A reassessment of the risk of multiple sclerosis developing in patients with optic neuritis after extended follow-up. Neurol Neurosurg Psychiatry 1987;50:758-65.

16 Rizzo JF, Lessell S. Risk of developing multiple sclerosis after uncomplicated optic neuritis. Neurology 1988 38:185-90.

17 McDonald WI. Doyne Lecture. The significance of optic neuritis. Trans Ophthal Soc UK 1983;103:230-46.

18 McDonald WI, Barnes D. Diseases of the optic nerve. In Asbury AK, McKhann GM, McDonald WI, eds. Diseases of the nervous system, 2nd ed. Philadelphia: WB Saunders, $1992 ; 421-33$.

19 Isayama Y, Takahashi T, Shimoyoma T, Yamadori A. Acute optic neuritis and multiple sclerosis. Neurology 1982; 32:73-6.

20 Alvarez G, Gardenas M. Multiple sclerosis following optic neuritis in Chile. $\mathcal{f}$ Neurol Neurosurg Psychiatry 1989; 52:115-7.

21 Hutchinson WM. Acute optic neuritis and the prognosis for multiple sclerosis. I Neurol Neurosurg Psychiatry 1976: 39:283-9.

22 Miller DH, Ormerod IEC, McDonald WI, et al. The early risk of multiple sclerosis after optic neuritis. $\mathcal{f}$ Neuro Neurosurg Psychiatry 1988;51:1569-71.

23 Dunn V, Bale JF, Zimmerman RA, Perdue Z, Bell WE. MRI in children with postinfectious disseminated encephalomyelitis. MRI 1986;4:25-32.

24 Kesselring J, Miller DH, Robb SA, et al. Acute disseminated encephalomyelitis-magnetic resonance imaging findings encephalomyelitis-magnetic resonance imaging findings 113:291-302.

25 Moulin D, Paty DW, Ebers GC. The predictive value of cerebrospinal fluid electrophoresis in "possible" multiple sclerosis. Brain 1983;106:809-16.

26 Hely MA, McManis PG, Doran TJ, et al. Acute optic neuritis: a prospective study of risk factors for multiple sclerosis. If Neurol Neurosurg Psychiatry 1986;49: 1125-30.

27 Compston DAS, Batchelor JR, Earl CJ, McDonald WI. Factors influencing the risk of multiple sclerosis developing in patients with optic neuritis. Brain 1978;101: 495-511.

28 Hawkins CP, Munro PMG, MacKenzie F, et al. Duration and selectivity of blood-brain barrier breakdown in chronic relapsing experimental allergic encephalomyelitis studied by gadolinium-DTPA and protein markers. Brain 1990;113:365-78.

29 Kermode AG, Thompson AJ, Tofts PS, et al. Breakdown of the blood-brain barrier precedes symptoms and other MRI signs of new lesions in multiple sclerosis. Brain 1990;113:1477-89.

30 Katz D, Taubenberger J, Raine C, McFarlin D, McFarland H. Gadolinium-enhancing lesions on magnetic resonance imaging: neuropathological findings. Ann Neurol 1990;28:243.

31 Thompson AJ, Kermode AG, Wicks D, et al. Major differences in the dynamics of primary and secondary
progressive multiple sclerosis. Ann Neurol 1991; progressive

32 Willoughby EW, Grochowski E, Li DKB, et al. Serial magnetic resonance scanning in multiple sclerosis: a second prospective study in relapsing patients. Ann Neurol 1989;25:43-9.

33 Youl BD, Turano G, Miller DH, et al. The pathophysiology of acute optic neuritis: an association of gadolinium leakage with clinical and electrophysiological deficits. Brain 1991;114:2437-50.

34 Halliday AM, McDonald WI, Mushin J. Delayed patternevoked responses in optic neuritis in relation to visual evoked responses in optic neuritis in relation
acuity. Trans Ophthal Soc UK 1973;93:315-24.

35 Smith KJ, McDonald WI. Spontaneous and mechanically evoked activity due to a central demyelinating lesion Nature 1980;286:154-5.

36 Miller DH, Moseley IF, Kendall BE, et al. Temporary reduction of blood-brain barrier impairment in multiple sclerosis by means of high dose steroid therapy. $\mathcal{F} \mathrm{Magn}$ Reson Imaging 1991;1:161.

37 Bowden AN, Bowden PMA, Friedman AI, Perkin GD, Clifford-Rose F. A trial of corticotrophin gelatin injection in acute optic neuritis. F Neurol Neurosurg Psychiatry 1974;37:869-73.

38 Rawson MD, Liversedge LA, Goldfarb G. Treatment of acute retrobulbar neuritis with corticotrophin. Lancet 1966;ii:1044-6.

39 Hierons R, Lyle TK. Bilateral retrobulbar optic neuritis. Brain 1959;82:56-67.

40 Parkin PJ, Hierons R, McDonald WI. Bilateral optic neuritis. A long-term follow up. Brain 1984;107:951-64.

41 Kermode AG, Moseley IF, Kendall BE. Magnetic resonance imaging in Leber's optic neuropathy. $\boldsymbol{f}$ Neurol Neurosurg Psychiatry 1989;52:671-4.

42 Wallace DC, Singh G, Lott MT, et al. Motochondrial DNA mutation associated with Leber's hereditary optic neuropathy. Science 1988;242:1427-30.

43 Holt IJ, Miller DH, Harding AE. Genetic heterogeneity and mitochondrial DNA heteroplasmy in Leber's hereditary mitochondrial Deuropathy. I Med Genet 1989;26:739-43.

44 Meadows SP. Retrobulbar and optic neuritis in childhood and adolescence. Trans Ophthal Soc UK 1969;89: and ado3-38.

45 Kriss A, Francis DA, Cuendet F, et al. Recovery after optic neuritis in childhood. $f$ Neurol Neurosurg Psychiatry 1988;51:1253-8.

46 Miller DH, Kay R, Schon F, McDonald WI, Haas LF, Hughes RAC. Optic neuritis following chickenpox in adults. F Neurol 1986;233:182-4.

47 Ormerod IEC, McDonald WI. Multiple sclerosis presenting with progressive visual failure. I Neurol Neurosurg Psychiatry 1984;47:943-6.

48 Hornabrook RSL, Miller DH, Newton MR, et al. Frequent involvement of the optic radiation in patients with acute isolated optic neuritis. Neurology 1992;42:77-9.

49 Plant GT, Kermode AG, Turano G, et al. Symptomatic retrochiasmal lesions in multiple sclerosis: clinical fearetrochiasmal lesions in multiple sclerosis: clinical features, visual evoked potentials and

50 Traquair HM. An introduction to clinical perimetry. 6th ed. London: Henry Kimpton, 1949.

51 Graham EM, Francis DA, Sanders MD, Rudge P. Ocular infalmmatory changes in established multiple sclerosis. $\mathscr{f}$ Neurol Neurosurg Psychiatry 1989;52:1360-3.

52 Bamford CR, Granley JP, Sibley WA, Laguna JM. Uveiitis, perivascular sheathing and multiple sclerosis. Neurology (NY) 1978;28 (suppl II): 119-24.

53 Graham EM, Ellis CJK, Sanders MD, McDonald WI. Optic neuropathy in sarcoidosis. $\mathcal{f}$ Neurol Neurosurg Psychiatry 1986;49:756-63. 